\title{
PENGARUH PENDIDIKAN SEBAYA (PEER EDUCATION) TERHADAP SIKAP DALAM PENCEGAHAN ANEMIA PADA REMAJA PUTRI DI POSYANDU REMAJA DESA PANDES KLATEN
}

\author{
Aulia Putti Utari, Gita Kostania, Suroso \\ Poltekkes Kemenkes Surakarta Jurusan Kebidanan \\ Diterima : 9 Januari 2019, Disetujui : 13 Februari 2019
}

\begin{abstract}
Background: The prevalence of anemia is still high among teenage girls aged 15-24 years $(18,4 \%)$, it can be caused by several things, one of them is due to the lack of public awareness (especially teenagers) about the prevention of iron deficiency anemia. To overcome this, it is necessary to intervene more upstream to groups of youth and teenegers. One of them is by increasing the knowledge of teenegers through peer education. Peers has a very high influence in attitudes. This is caused by teens tend to choose the same attitude with their peers to be accepted by the group. The purpose of this study is to determine the effect of peer education on attitudes about anemia prevention among teenage girls in "Posyandu" Pandes, Klaten. Method: The type of this study was a Pre-Experiment design with one group pre-post test approach. Sampling technique that used was cluster sampling, the number of samples obtained 60 teenage girls as respondents in Pandes, Klaten. Data collected was using questionnaires on anemia prevention and data analysis technique that used was paired t-test parametric statistic with significance level of 0,05. Results: The attitude of teenage girls in anemia prevention is positive with pretest's mean was 51,42 and posttest's mean was 53,92. Conclusion: The p-value indicated the result of 0,001 ( $p<$ $0,05)$. Peer education had an effect on attitude in anemia prevention.
\end{abstract}

Keywords: Peer Education, Attitude, Prevention of Anemia.

\section{PENDAHULUAN}

Berdasarkan Riset Kesehatan Dasar (2013), ditemukan proporsi anemia pada remaja (15-24 tahun) sebesar 18,4\%, sementara di Kabupaten Klaten yaitu sebanyak $727(1,45 \%)$ remaja putri usia 10-14 tahun serta $1006(2,03 \%)$ remaja putri usia 15-18 tahun terdeteksi anemia. Data tersebut juga tidak bisa seluruhnya menggambarkan keadaan yang sebenarnya, karena tidak semua daerah melakukan skrining untuk anemia pada remaja (DKK Klaten, 2016). Dari data inilah menunjukkan bahwa kejadian anemia pada remaja putri masih tinggi, karena prevalensi anemia dianggap menjadi masalah kesehatan jika $>15 \%$.

Salah satu penyebab tingginya prevalensi anemia yaitu karena masih minimnya kesadaran masyarakat (remaja) tentang upaya pencegahan anemia defisiensi zat besi akibat kurang terpapar informasi khususnya tentang gizi seimbang. Mengatasi hal tersebut, perlu dilakukan intervensi lebih ke hulu yakni kepada kelompok remaja dan dewasa muda dengan meningkatkan pengetahuan remaja tentang anemia melalui pendidikan sebaya. Pada remaja di sekolah menengah dan perguruan tinggi, teman sebaya 
mempunyai pengaruh yang sangat tinggi dalam pembentukan sikap. Mereka akan cenderung memilih sikap yang sama dengan anggota sebayanya, agar mereka dapat diterima oleh kelompoknya (Purnomo, 2013). Hal inilah yang mendorong peneliti melakukan penelitian tentang pengaruh pendidikan sebaya terhadap sikap dalam pencegahan anemia pada remaja putri.

Penelitian ini bertujuan untuk mengetahui pengaruh pendidikan sebaya terhadap sikap dalam pencegahan anemia pada remaja putri.

\section{METODE PENELITIAN}

Jenis penelitian pra eksperimental dengan pendekatan one group pre test post test design yaitu dengan melihat perubahan sikap dalam pencegahan anemia sebelum dan setelah diberikan pendidikan sebaya.

Penelitian ini dilakukan di Desa Pandes Kecamatan Klaten Selatan Kabupaten Klaten pada bulan Agustus 2017 s/d Januari 2018. Populasi dalam penelitian ini adalah seluruh remaja putri di Desa Pandes berjumlah 237 remaja putri. Pengambilan sampel secara cluster sampling. Penentuan kelompok yang dijadikan sampel dilakukan secara acak, maka didapatlah 4 dukuh sebagai sampel penelitian.

Instrumen penelitian ini berupa kuisioner (tertutup) sikap dengan skala likert dalam dua bentuk pernyataan yakni pernyataan positif dan negatif yang seluruhnya berjumlah 17 pernyataan. Pengumpulan data dilakukan oleh peneliti pada tanggal 5 November 2017 s/d tanggal 2 Desember 2017.

Analisa data pada penelitian ini menggunakan statistik parametrik yaitu pengujian paired t-test. Pengujian dilakukan dengan bantuan program komputer SPSS 20 for windows.

\section{HASIL PENELITIAN}

1. Analisis Univariat

Analisis univariat digunakan untuk mengetahui distribusi frekuensi, tendency central dan variasi data hasil sikap sebelum dan sesudah dilakukan pendidikan sebaya.

Tabel 1. Distribusi Frekuensi Responden Berdasarkan Umur, Pendidikan, Keterpaparan Informasi tentang Anemia dan Riwayat Anemia.

\begin{tabular}{|c|c|c|c|}
\hline No. & Karakteristik & $\mathbf{f}$ & $\%$ \\
\hline \multirow{6}{*}{1.} & Umur & & \\
\hline & a. Remaja awal & 30 & 50,0 \\
\hline & b. Remaja & 24 & 40,0 \\
\hline & menengah & 6 & 10,0 \\
\hline & c. Remaja akhir & & \\
\hline & Total & 60 & 100,0 \\
\hline \multirow{6}{*}{2.} & Tingkat Pendidikan & & \\
\hline & a. Pendidikan dasar & 30 & 50,0 \\
\hline & b. Pendidikan & 26 & 43,3 \\
\hline & menengah & 4 & 6,7 \\
\hline & $\begin{array}{l}\text { c. Pendidikan } \\
\text { tinggi }\end{array}$ & & \\
\hline & Total & 60 & 100,0 \\
\hline \multirow{5}{*}{3.} & Keterpaparan & & \\
\hline & Informasi & 20 & 33,3 \\
\hline & a. Pernah & 40 & 66,7 \\
\hline & b. Belum pernah & & \\
\hline & Total & 60 & 100,0 \\
\hline \multirow{4}{*}{4.} & Riwayat Anemia & & \\
\hline & a. Ada & 40 & 66,7 \\
\hline & b. Tidak ada & 20 & 33,3 \\
\hline & Total & 60 & 100,0 \\
\hline
\end{tabular}

Berdasarkan tabel 1. karakteristik responden menunjukkan hasil bahwa sebanyak 30 responden $(50 \%)$ dalam kategori remaja awal (11-14 tahun) dan paling sedikit 6 responden $(10 \%)$ dalam kategori remaja akhir (18-20 tahun). Berdasarkan tingkat pendidikan, hasil menunjukkan bahwa sebanyak 30 responden $(50 \%)$ dengan latar belakang 
pendidikan dasar dan sebanyak 26 responden $(43,3 \%)$ dengan latar belakang pendidikan menengah. Karakteristik responden berdasarkan keterpaparan informasi

tentang anemia didapatkan bahwa sebagian besar responden $(66,7 \%)$ belum pernah mendapatkan informasi tentang Anemia dan sebanyak 20 responden $(33,3 \%)$ sudah pernah mendapatkan informasi tentang anemia, sedangkan karakteristik responden berdasarkan riwayat anemia menunjukkan hasil bahwa sebagian besar responden $(66,7 \%)$ pernah mengalami gejala anemia.

Tabel 2. Distribusi Frekuensi Sikap Responden Sebelum dan Setelah Dilakukan Pendidikan Sebaya

\begin{tabular}{lrrrr}
\hline Pendidikan & \multirow{2}{*}{$\begin{array}{c}\text { Sampel } \\
\text { sebaya }\end{array}$} & \multicolumn{2}{c}{ Skor } & \multicolumn{2}{c}{ Mean } \\
\cline { 3 - 4 } & Min & Maks & $(\overline{\boldsymbol{x}})$ \\
\hline Sebelum & \multirow{2}{*}{60} & 44 & 65 & 51,42 \\
Sesudah & & 51 & 67 & 53,92 \\
\hline
\end{tabular}

Berdasarkan tabel 2. di atas dapat dijelaskan bahwa sebelum dilakukan pendidikan sebaya tentang pencegahan anemia, skor terendah responden adalah 44 dan skor tertinggi 65. Rata-rata skor pretest responden adalah 51,42 dan masuk dalam kategori positif, sedangkan setelah dilakukan pendidikan sebaya tentang pencegahan anemia, skor terendah responden adalah 51 dan skor tertinggi 67. Rata-rata skor posttest responden adalah 53,92 dan masuk dalam kategori positif.

Berdasarkan uji statistik menggunakan uji paired t-test dengan program SPSS, didapatkan nilai $t$ test $=$ 12,730 dan $p$ value $=0,001(p<0,05)$. Dari hasil tersebut dapat dijelaskan terdapat pengaruh pemberian pendidikan sebaya terhadap sikap dalam pencegahan anemia pada remaja putri di posyandu remaja Desa Pandes.

\section{PEMBAHASAN}

Hitchcock, et al dalam Aisha (2008) mengungkapkan bahwa teman sebaya dan lingkungan sosial mempunyai dampak kuat pada remaja terhadap pola makan, edukasi ilmu gizi dan lainnya. Demikian juga yang diungkapkan Pender, et al dalam Aisha (2008) bahwa proses yang terjadi di dalam kegiatan kelompok sebaya berorientasi pada perilaku dan kognitif.

Pendidikan sebaya memiliki pengaruh terhadap sikap dalam pencegahan anemia pada remaja putri. Namun dari uraian beberapa hasil penelitian terkait data karakteristik responden di atas mulai dari umur, pendidikan, keterpaparan informasi tentang anemia, dan riwayat anemia, pendidikan sebaya tidak serta merta menjadi faktor satu-satunya dalam mempengaruhi sikap dalam pencegahan anemia. Berdasarkan hasil analisis karakteristik responden, keterpaparan informasi tentang anemia dan riwayat anemia menjadi salah satu faktor pendorong perubahan sikap dalam pencegahan anemia. Hal ini sesuai dengan Notoatmodjo (2012) yang menyatakan bahwa terdapat beberapa faktor-faktor yang mempengaruhi sikap seseorang antara lain pengetahuan atau pendidikan dan pengalaman pribadi.

Dalam pendidikan sebaya remaja dapat lebih terbuka dan percaya dalam menyampaikan pikirannya karena remaja sudah merasa akrab terlebih dahulu dengan peer educator, sehingga tidak ada ketakutan dari setiap individu dalam bertanya ataupun berpendapat. Menurut Clayton dan Mercer dalam Setyaningsih (2016) menjelaskan bahwa keakraban dengan suatu objek dapat mendorong sikap positif terhadap objek tersebut. 
Orang yang paling sering ditemui dan berinteraksi adalah yang paling mungkin menjadi teman sehingga menimbulkan keakraban. Sehingga pada pemilihan pendidik sebaya dalam penelitian ini, diupayakan mereka yang mempunyai pengaruh dan menjadi panutan pada teman sebayanya.

Pemenuhan kebutuhan emosional individu mulai beralih dari orang tua ke teman sebaya saat masa remaja. Dukungan antar teman sebaya dalam pendidikan sebaya ini dapat menjadi wadah dalam meningkatkan partisipasi remaja untuk mengikuti program pendidikan kesehatan. Remaja akan lebih terbuka dan percaya dalam menyampaikan hal-hal yang sensitif bahkan di luar topik pembahasan dan masalah yang ada dapat diselesaikan dengan mudah melalui pendidikan sebaya. Hal tersebut didukung oleh penelitian Irawati (2013) bahwa mayoritas remaja menghabiskan waktu bersama teman-temannya melebihi waktu yang dihabiskan dengan orang tua dan anggota keluarga lainnya, sehingga pengaruh teman sebaya lebih besar dari pengaruh keluarga.

Pendidikan sebaya bahkan digunakan sebagai metode dalam pendidikan formal di perguruan tinggi seperti dalam penelitian Grover, et al (2017) tentang Pathology Reform by PeerAssisted Learning yakni mereformasi ajaran patologi di perguruan tinggi kedokteran dengan pembelajaran dimana siswa bertindak sebagai guru sebaya dan membantu siswa lain untuk belajar. Penelitian ini bertujuan untuk mengevaluasi kegunaan peer teaching dengan mendapatkan umpan balik dari siswa. Hasil penelitian menunjukkan bahwa siswa lebih mudah dalam memahami dan berinteraksi serta keterlibatan siswa sebagai manfaat terpenting pembelajaran peer assisted. Hal inilah yang mendukung pemberian informasi mengenai pencegahan anemia lebih besar pengaruhnya apabila diberikan oleh teman sebaya melalui pendidikan sebaya.

Dalam penelitian ini, tidak dilakukan kontrol karakteristik umur responden dikarenakan peneliti kesulitan dalam mencari dan mengelompokkan sampel dalam kategori remaja awal, remaja akhir dan remaja menengah dalam waktu yang singkat di komunitas. Penelitian ini juga hanya meneliti aspek sikap remaja putri dalam pencegahan anemia. Penelitian ini belum meneliti aspek perilaku remaja putri dalam pencegahan dan penanggulangan anemia sebagai hasil dari pendidikan kesehatan dan pembentukan sikap dalam pencegahan anemia.

\section{KESIMPULAN DAN SARAN}

Ada pengaruh yang bermakna pendidikan sebaya terhadap sikap remaja putri dalam pencegahan anemia di posyandu remaja desa pandes sehingga diharapkan dalam meningkatkan kesehatan di komunitas, bidan dapat melakukan kegiatan pemberdayaan masyarakat melalui pendidikan dan pelatihan pada perwakilan di masyarakat khususnya kelompok remaja yang aktif, sehingga perwakilan remaja tersebut dapat memotivasi remaja lain atau teman sebayanya dalam peningkatan kesehatan reproduksi remaja. Bagi remaja diharapkan dapat memotivasi teman sebaya agar mencegah terjadinya anemia sehingga dapat menjadi remaja yang produktif dan calon ibu yang sehat. Selain itu, diharapkan kepada peneliti selanjutnya dapat melakukan kontrol pada karakteristik umur responden dan meneliti 
tentang sikap serta perilaku dalam Hadiningsih, T. (2008). Hubungan pencegahan anemia.

\section{DAFTAR RUJUKAN}

Arikunto. (2010). Prosedur Penelitian Suatu Pendekatan Praktik. Jakarta: Rineka Cipta

Aisah, St. (2008). Pengaruh Edukasi Kelompok Sebaya terhadap Perubahan Perilaku Pencegahan Anemia Gizi Besi pada Wanita Usia Subur di Kota Semarang. http://eriset.unimus.ac.id, diperoleh 29 Agustus 2017

BKKBN. (2008). Kurikulum dan Modul Pelatihan Pengelolaan Pemberian Informasi Kesehatan Reproduksi Remaja oleh Pendidik Sebaya. http://ceria.bkkbn.go.id, diperoleh 29 Agustus 2017

Briawan, Dodik. (2013). Anemia Masalah Gizi pada Remaja Wanita. Jakarta: EGC

Budiman., \& Riyanto, Agus. (2014). Kapita Selekta Kuisioner Pengetahuan dan Sikap dalam Penelitian Kesehatan. Jakarta: Salemba Medika

Dinkes Kabupaten Klaten. (2016). Profil Kesehatan Kabupaten Klaten Tahun 2016. Klaten: Dinkes Kabupaten Klaten

Emilia, Ova. (2008). Promosi Kesehatan dalam Lingkup Kesehatan Reproduksi. Yogyakarta: Pustaka Cendekia Press

Grover, Sumit et al. (2017). Reforming Pathology Teaching in Medical College by Peer-Assisted Learning and Student-Oriented Interest Building Activities. http://www.educationforhealth.net, diperoleh 4 Januari 2018

Tingkat Pengetahuan Remaja Putri tentang Anemia Gizi Besi dengan Motivasi untuk Melakukan Upaya Pencegahan terhadap Anemia Gizi Besi di SMU Negeri 40 Jakarta Utara. Tesis. Tidak dipublikasikan: Universitas Indonesia.

Handayani, W., \& Hariwibowo, S. (2008). Asuhan Keperawatan pada Klien dengan Gangguan Sistem Hematologi. Jakarta: Salemba Medika

Hidayat, A.A. 2014. Metode Penelitian Keperawatan dan Teknis Analisis Data. Jakarta: Salemba Medika

Imron, Ali. (2012). Pendidikan Kesehatan Reproduksi Remaja. Yogyakarta: Ar Ruzz Media

Kementerian Kesehatan RI. 2016. Jurnal Kesehatan Reproduksi. http://ejournal.litbang.depkes.go.id , diperoleh tanggal 27 Agustus 2017

Kiswari, Rukman. (2014). Hematologi dan Transfusi. Jakarta: Erlangga

Notoatmodjo, S. (2010). Metodologi Penelitian Kesehatan. Jakarta: Rineka Cipta

Notoatmodjo, Soekidjo. (2012). Promosi Kesehatan dan Perilaku Kesehatan. Jakarta: Rineka Cipta

Parmaesih, Dewi., \& Herman, Susilowati. (2005). Faktor-Faktor yang Mempengaruhi Anemia Pada Remaja. http://ejournal.litbang.kemkes.go.i $\underline{d}$, diperoleh 27 Agustus 2017

Purnomo, Indra. (2013). Perbandingan Pengaruh Metode Pendidikan Sebaya dan Metode Caramah terhadap Pengetahuan dan Sikap PengendalianHIV/AIDS pada Mahasiswa Fakultas Olahraga dan 
56 Jurnal Kebidanan Dan Kesehatan Tradisional, Volume 4, No 1, Maret 2019, hlm 1-56

Kesehatan Universitas Pendidikan

Ganesha. digilib.uns.ac.id, diperoleh tanggal 29 Agustus 2018

Riskesdas. (2013). Riset Kesehatan Dasar 2013.

http://www.depkes.go.id/resources/ download/general/Hasil\%20Riskes das\%202013.pdf, diperoleh tanggal 27 Agustus 2017

Simamora, Bilson. (2008). Panduan Riset Perilaku Konsumen. Jakarta:

Gramedia Pustaka Utama

Sugiyono, (2010). Metode Penelitian Kuantitatif, Kualitatif $R \& D$, Bandung: Alfabeta. 